\title{
Solanum lycopersicum (tomato) ethanol extract elicits anti-inflammatory effects via the nuclear factor kappa $B$ pathway and rescues mice from septic shock
}

\author{
Evelyn Saba ${ }^{1}$, Mi-Ju Oh ${ }^{1}$, Dongmi Kwak ${ }^{1}$, Seong-Soo Roh ${ }^{2}$, Hyuk-Woo Kwon ${ }^{1}$, Sung-Dae Kim ${ }^{1}$, Man Hee Rhee ${ }^{1, *}$ \\ ${ }^{1}$ Department of Veterinary Medicine, College of Veterinary Medicine, Kyungpook National University, \\ Daegu 41566, Korea \\ ${ }^{2}$ College of Korean Medicine, Daegu Hanny University, Gyeongsan 38610, Korea
}

(Received: March 21, 2017; Revised: May 16, 2017; Accepted: May 19, 2017)

\begin{abstract}
Solanum lycopersicum, commonly known as tomato, is widely used in raw, cooked, or liquid forms because it contains nutritional compounds that are beneficial for human health, including carotenoids, lycopene, ascorbic acid, vitamins, and minerals. The tomato is perhaps the most widely studied fruit, especially with respect to its cardioprotective effects. In this study, we aimed to identify the anti-inflammatory mechanisms by which the tomato elicits its antiinflammatory properties. We treated murine macrophage RAW 264.7 cells with a tomato ethanol extract and performed various biochemical assays including nitric oxide inhibition, cell viability, RNA extraction, expression of proinflammatory mediators and cytokines, and immunoblotting, as well we assessed cell survival rates. Our results have shown for the first time that a tomato ethanol extract treatment can suppress nitric oxide production in a dose-dependent manner without cytotoxicity. Moreover, it inhibits the expression of pro-inflammatory mediators and cytokines and elicits its anti-inflammatory effects via the nuclear factor kappa-light-chain-enhancer of activated B cells (NF- $\kappa \mathrm{B})$ and mitogen-activated protein kinase (MAPK) pathways. In addition, administration of tomato syrup potently rescued mice from septic shock induced by lipopolysaccharide injection. Collectively, our results elucidate details regarding the antiinflammatory mechanisms of tomato.
\end{abstract}

Keywords: anti-inflammation, cytokines, pro-inflammatory mediators, septic shock, tomato ethanol extract

\section{Introduction}

The growing incidence of cardiovascular, immunosuppressive and chronic inflammatory diseases due to the rapid pace of industrialization poses a serious threat for the well-being of mankind. The increased amounts of social, personal, and workplace stress cannot be ignored as factors predisposing humans to premature aging, mental illnesses and early deaths [19]. Rapid and ongoing global research towards a cure for various chronic diseases has altogether contributed positively towards the health of mankind. However, the serious disadvantages of these chemical orientated medicines cannot be ignored. In order to avoid the side effects of these chemical medications, scientists all over the world are struggling to improve health conditions by using natural products like fruits and vegetables. Solanum lycopersicum commonly known as tomato is widely consumed as fruit and vegetable all over the world. The anti-oxidant, anti-inflammatory, anti-diabetic, and anti-lipidemic activities of the tomato have been studied extensively in the past and currently $[1,9]$. The protective properties of tomato are mainly attributed to the carotenoid, lycopene, which is present in great quantities within the fruit. There is much ongoing research on the tomato as a whole fruit, or isolated lycopene, which is the most abundant and active component of the tomato. Lycopene administration alleviated prostitis in a manner comparable to that of ciprofloxacin [14]. Furthermore it reduced the chemical and histological symptoms in iodoacetamide induced colitis in rats [28]. Anthocyanins from tomatoes have also been shown to exhibit inhibitory effects on inducible nitric oxide synthase (iNOS) and cyclooxygenase-2 (COX-2) [12].

Inflammation is the hallmark of almost every disease and if not controlled at proper time point, can lead to chronic diseases. The production of pro-inflammatory cytokines when the body encounters a foreign invader is a primary response of immune cells [21]. These pro-inflammatory cytokines and mediators further recruit more potent chemicals and cells, such as natural killer cells, that neutralize and destroy the for-

*Corresponding author

Tel: +82-53-950-5967, Fax: +82-53-950-5955

E-mail: rheemh@knu.ac.kr 
eign particle. Macrophages are the cells that phagocytize foreign particles and signal the recruitment of other cells via production of inflammatory mediators like iNOS, COX-2 and pro-inflammatory cytokines including interleukin (IL)$1 \beta, 1 \mathrm{~L}-6$ and tumor necrosis factor (TNF)- $\alpha$ [29]. Production of pro-inflammatory mediators leads to the activation of pro-inflammatory cytokines [8]. All of these chemicals when released synchronously, fight against foreign materials and alleviate infection through the nuclear factor kappa-lightchain-enhancer of activated B cells $(\mathrm{NF}-\kappa \mathrm{B})$ and mitogenactivated protein kinase (MAPK) pathways [30].

Previously we have shown the antiplatelet effects of the tomato extract [16], but here in this study, we geared to elucidate the detailed anti-inflammatory mechanisms of whole tomato ethanol extract in vitro using RAW 264.7 cells and in vivo using a septic shock ICR mouse model. It is a wellknown and alarming fact that the cause of most post-operative mortalities or bacterial infections is due to severe septic shock which is defined as the systemic distribution of bacterial toxins in body leading to death [22].

\section{Materials and Methods}

\section{Materials}

Dulbecco's modified Eagle's medium (DMEM) and fetal bovine serum (FBS) were purchased from WELGENE (Korea). Total RNA extraction kit was purchased from Invitrogen (USA). Oligo dT, iNOS, COX-2, TNF- $\alpha$, IL-6, and IL-1 $\beta$ primers were obtained from Bioneer (Korea). Lipopolysaccharide (LPS; Escherichia coli 055: B5) and 3-(4,5-dimethylthiazol-2-yl)-2,5-diphenyltetrazoliumbromide (MTT) were purchased from Sigma Aldrich (USA). Specific antibodies used against phospho- and/or total form of extracellular signalregulated kinase (ERK), c-Jun N-terminal kinase (JNK), p38, nuclear factor of kappa light polypeptide gene enhancer in $\mathrm{B}$ cells inhibitor (I $\mathrm{B}$ ), I $\mathrm{I} B$ kinase (IKK) $\alpha / \beta, \mathrm{NF}-\kappa \mathrm{B}$ p65 and $\beta$-actin as well as rabbit HRP linked secondary antibody were purchased from Cell Signaling Technology (USA). All other reagents and chemicals were obtained from Sigma Aldrich.

\section{Animal studies}

Male ICR mice (26-29g) were purchased from Charles River, Orient Biotechnology, Gyeonggi-do, South Korea. The mice were housed in a specific pathogen free barrier facility at $21 \pm 2{ }^{\circ} \mathrm{C}$ with a relative humidity of $60 \pm 10 \%$ under a $12 \mathrm{~h}$ light and dark cycle. Feed and water were provided ad libitum. All animal care and experimental procedures were approved by Animal Care Committee (2015-0062) of Kyungpook National University, Daegu, South Korea. The mice were divided into 3 groups with each group $(n=10)$ for survival study. Group 1 was taken as control or vehicle treated group. Group 2 was LPS control group and Group 3 was treated with water soluble tomato concentrate (DSM Nutritional Product; DSM, Switzerland) [16], which we named as tomato syrup for 3 days prior to LPS injection orally at a dose of $900 \mathrm{mg} / \mathrm{kg}$ once a day based on the equivalent human consumption of tomato per day which is $3 \mathrm{~g} /$ day. The amount of lycopene present in the tomato syrup was around $3-5 \mathrm{mg} / 100 \mathrm{~g}$ fresh tomatoes $[6,32]$. After the pretreatment of mice with tomato syrup for three days, at the fourth day groups 2 and 3 were given LPS intraperitoneally at $30 \mathrm{mg} / \mathrm{kg}$ and then the survival rate was monitored for $96 \mathrm{~h}$.

\section{Tomato ethanol extract (TEE) preparation}

Whole dried tomatoes were condensed using $70 \%$ ethanol in a 20-fold volume. After condensation, the ethanol extract was filtered through a $2 \mu \mathrm{m}$ pore Whatman filter paper. The filtrate was then frozen at $-70^{\circ} \mathrm{C}$ for 2 days and then vacuum dried to obtain a powered form. The powdered form was then weighed and diluted in dimethyl sulfoxide (DMSO) and used accordingly for each experiment.

\section{Cell culture}

RAW 264.7 cells, murine macrophage cell line, originating from American Type Culture Collection (ATCC-TIB-71) were cultured in complete DMEM supplemented with 5\% FBS, penicillin $(100 \mathrm{IU} / \mathrm{mL})$ and streptomycin sulfate $(100$ $\mu \mathrm{g} / \mathrm{mL}$ ) in humidified $5 \% \mathrm{CO}_{2}$ incubator at $37^{\circ} \mathrm{C}$.

\section{Nitric oxide assay}

Nitric oxide (NO) measurements were performed on the basis of Griess reaction. In short, RAW 264.7 cells were seeded in 96-well plates and incubated with or without LPS $(0.1 \mu \mathrm{g} / \mathrm{mL})$ in the absence or presence of TEE at concentrations of $250-1,000 \mu \mathrm{g} / \mathrm{mL}$ for $18 \mathrm{~h}$. Next day, the culture supernatants $(100 \mu \mathrm{L})$ were mixed with Griess reagent $(0.2 \%$ naphthyl ethylene diamine dihydrochloride, and $2 \%$ sulphanilamide in 5\% phosphoric acid) in double distilled water at equal volumes and incubated for $5 \mathrm{~min}$ at room temperature. The absorbance in each well was then read at $540 \mathrm{~nm}$ in enzyme-linked immunosorbent assay reader (VersaMax ELISA Microplate Reader; Molecular Devices, USA).

\section{Cell viability assay}

Cytotoxic effects of TEE were examined using MTT reagent which was added to culture medium at a final concentration of $0.1 \mathrm{mg} / \mathrm{mL}$ in 96 -well plate. After $4 \mathrm{~h}$ of incubation at $37^{\circ} \mathrm{C}$ in $5 \% \mathrm{CO}_{2}$, the violet coloured crystals were dissolved in DMSO $(100 \mu \mathrm{L} /$ well) and absorbance values were read at 560 nm (VersaMax Microplate Reader; Molecular Devices).

RNA extraction and quantitative real-time polymerase chain reaction (qRT-PCR)

RAW 264.7 cells were pre-treated with or without TEE at indicated concentrations for $30 \mathrm{~min}$ and then stimulated with LPS $(0.1 \mu \mathrm{g} / \mathrm{mL})$ for $18 \mathrm{~h}$ in 6 -well plates. Total RNA was extracted using a TRIZOL reagent (Invitrogen, USA) following the manufacturer's instructions. Subsequent steps for 
Table 1. Primer sequences used for polymerase chain reaction

\begin{tabular}{ccl}
\hline \hline Gene & Primer & \multicolumn{1}{c}{ Oligonucleotide sequence (5'-3') } \\
\hline \multirow{2}{*}{ GAPDH } & F & 5'CAATGAATACGGCTACAGCAAC3' \\
& R & 5'AGGGAGATGCTCAGTGTTGG3' \\
\multirow{2}{*}{ iNOS } & F & 5'CCCTTCCGAAGTTCTGGCAGCAGC3' \\
& R & 5'GGCTGTCAGAGCCTCGTGGCTTTGG3' \\
COX-2 & F & 5'-TCTCAGCACCCACCCGCTCA-3' \\
& R & 5'-GCCCCGTAGACCCTGCTCGA-3' \\
IL-1 $\beta$ & F & 5'CAGGGTGGGTGTGCCGTCTTTC3' \\
& R & 5'TGCTTCCAAACCTTTGACCTGGGC3' \\
TNF- $\alpha$ & F & 5'TTGACCTCAGCGCTGAGTTG3' \\
& R & 5'CCTGTAGCCCACGTCGTAGC3' \\
IL-6 & F & 5'-GTACTCCAGAAGACCAGAGG-3' \\
& R & 5'-TGCTGGTGACAACCACGGCC-3'
\end{tabular}

F, forward; R, reverse.

A

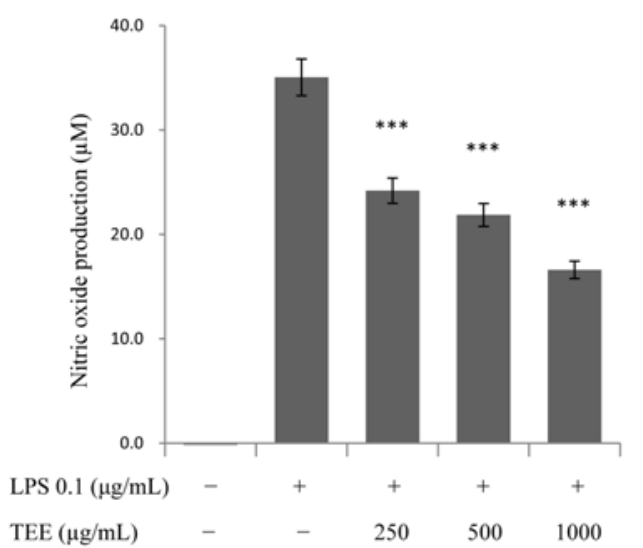

B

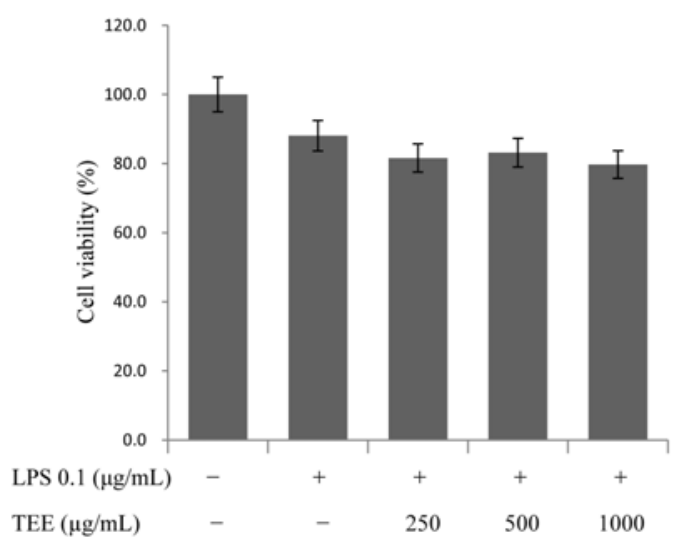

Fig. 1. Inhibition of nitric oxide (NO) by tomato ethanol extract (TEE). RAW 264.7 cells were preincubated with TEE for 30 min and then stimulated with lipopolysaccharide (LPS) for $18 \mathrm{~h}$. Cell supernatant was then mixed with equal amounts of Griess reagent and NO production was measured (A). Effects of TEE on cell viability were measured by MTT assay (B). Values in bar graph are mean \pm SEM of three independent experiments. ${ }^{* * *} p<0.001$ are considered significant compared to LPS group only.

cDNA for qRT-PCR were according to previous study [31]. Quantitative PCR primer sequences are given in Table 1.

\section{Western blot analysis}

Cytosolic and nuclear proteins were extracted according to manufacturer's instructions using NE-PER nuclear and cytosolic extraction reagents (No. 78833 and No. 78835; Thermo Scientific, USA) from RAW264.7 cells when they were treated or untreated with TEE $(250-1,000 \mu \mathrm{g} / \mathrm{mL})$ in the presence or absence of LPS $(0.1 \mu \mathrm{g} / \mathrm{mL})$ in 6-well plates. Protein quantification was then performed using PRO-MEASURE assay kit (iNtRON Biotechnology, Korea). Proteins were then loaded onto $10 \%$ acrylamide gels, separated by SDS-PAGE and transferred onto PVDF membranes (Immobilon-P; Millipore, USA). Nonspecific binding on PVDF membranes was minimized with a blocking buffer containing 5\% non-fat dry milk and $0.1 \%$ Tween-20 in Tris-buffered saline. The membranes were then incubated with specific primary antibodies overnight at $4^{\circ} \mathrm{C}$ followed by $1 \mathrm{~h}$ incubation with HRP-conjugated anti-rabbit antibody (1:3,000 dilution, Cell Signaling Technology). Bound antibodies were visualized using enhanced chemiluminescence (SUPEX ECL solution; Neuronex, Korea) and images were analyzed using ImageJ 2 software (National Center for Biotechnology Information, USA). $\beta$-actin was used as an internal control.

\section{Statistical analysis}

Data are presented as mean \pm SEM. One-way analysis of variance followed by Dunnett's -test was used for statistical analysis. SAS 9.3 (SAS Institute, USA) was applied for analysis. $P$ values less than 0.01 were considered statistically significant. 
A

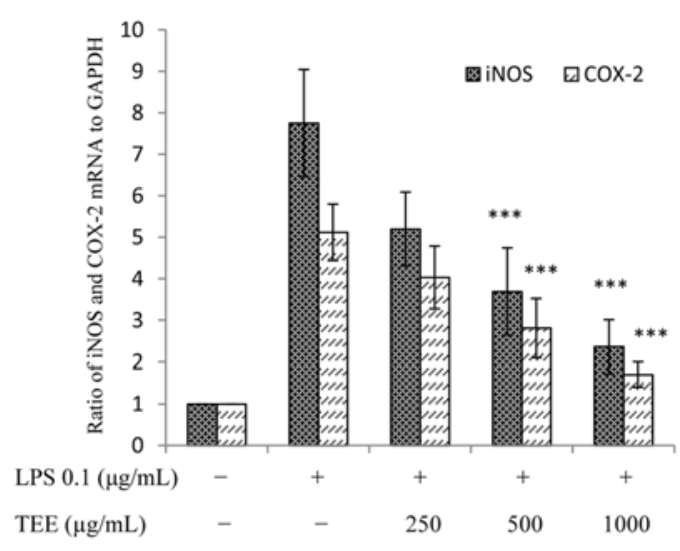

B
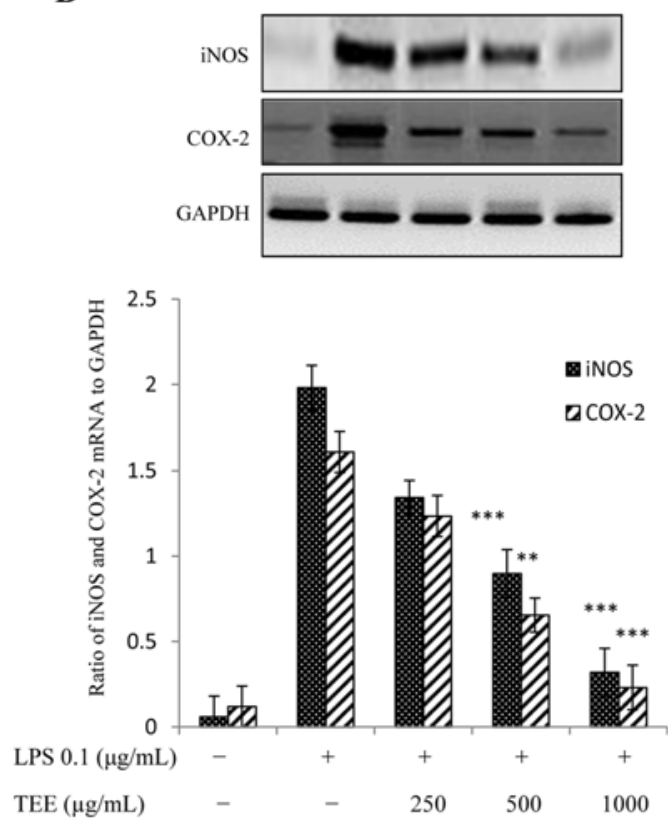

Fig. 2. TEE suppressed pro-inflammatory mediators. RAW 264.7 cells were preincubated with TEE for 30 min and then stimulated with LPS for $18 \mathrm{~h}$. Total RNA was extracted and mRNA expression of inducible nitric oxide synthase (iNOS) and cyclooxygenase2 (COX-2) was determined both by real-time (A) and reverse transcriptase polymerase chain reaction (B). GAPDH was used as an internal control. Image is representative of three independent experiments. Values in bar graphs are mean \pm SEM of three independent experiments. ${ }^{* * *} p<0.001$ and ${ }^{* *} p<0.05$ are considered significant compared to LPS group only.

A

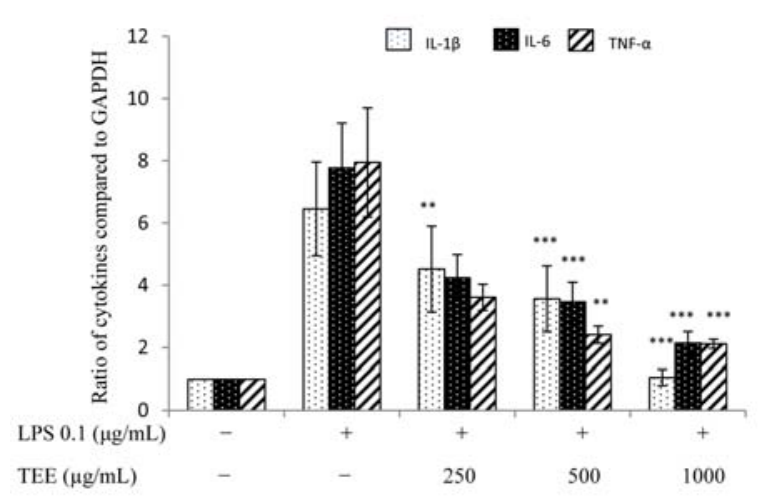

B

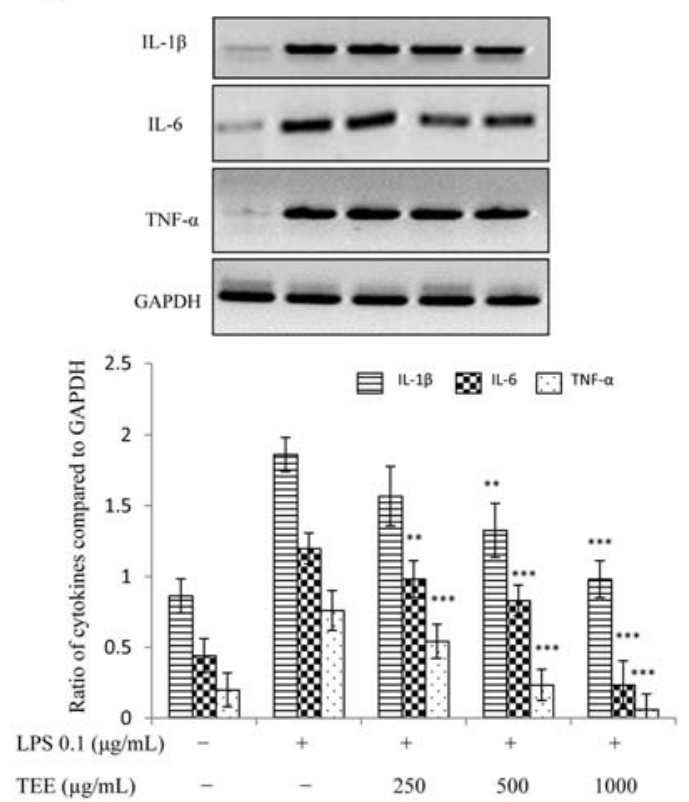

Fig. 3. Expression of pro-inflammatory cytokines was diminished by TEE. For mRNA expression, RAW 264.7 cells were pre-treated with TEE for $30 \mathrm{~min}$ and then stimulated with LPS for $18 \mathrm{~h}$. Total RNA was extracted and mRNA expression of interleukin (IL)$1 \beta$, IL- 6 and tumor necrosis factor (TNF)- $\alpha$ was determined by real-time PCR (A) and RT-PCR (B). GAPDH was used as an internal control. Image is representative of three independent experiments. Values in bar graphs are mean \pm SEM of three independent experiments. ${ }^{* * *} p<0.001$ and ${ }^{* *} p<0.05$ are considered significant compared to LPS group only. 


\section{Results}

\section{TEE inhibited LPS induced inflammation in RAW} 264.7 cells

NO is produced when bacterial lipopolysaccharides bind to the Toll like receptors. Therefore, we sought to check the inhibition of NO by TEE. As shown in Fig. 1A, TEE signif- icantly suppressed the NO production in a dose dependent manner without any cytotoxicity (Fig. 1B).

\section{Suppression of pro-inflammatory mediators by TEE}

In our result, we found that TEE suppressed the expression of pro-inflammatory mediators that are iNOS and COX2 at transcriptional level as shown in Fig. 2A and B.

A

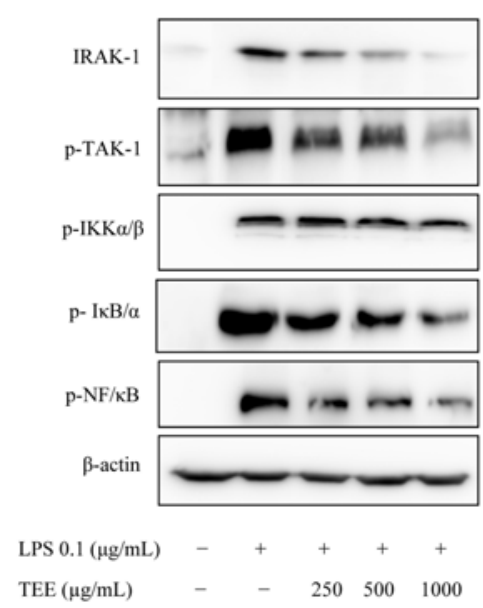

B
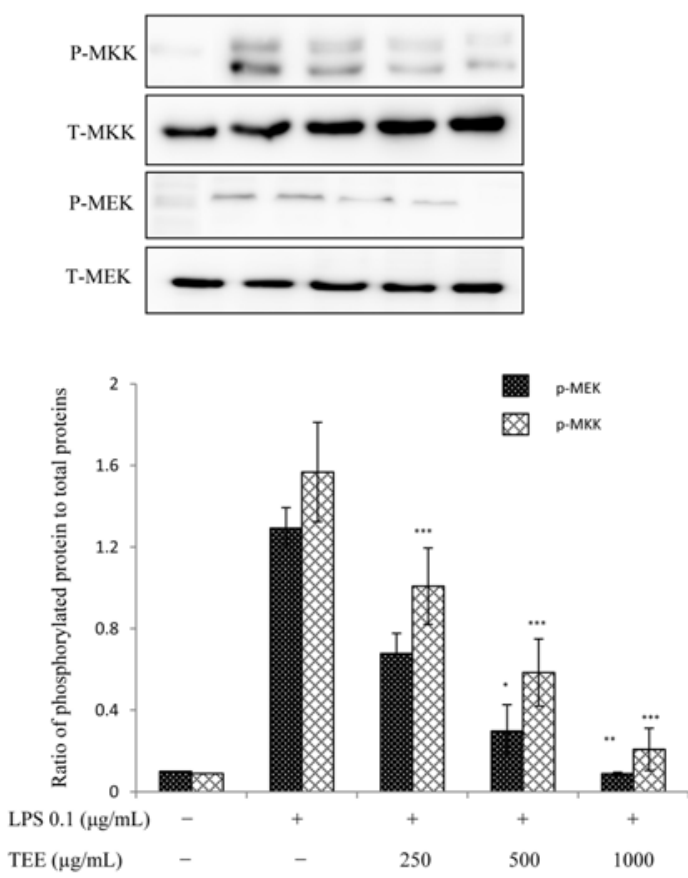

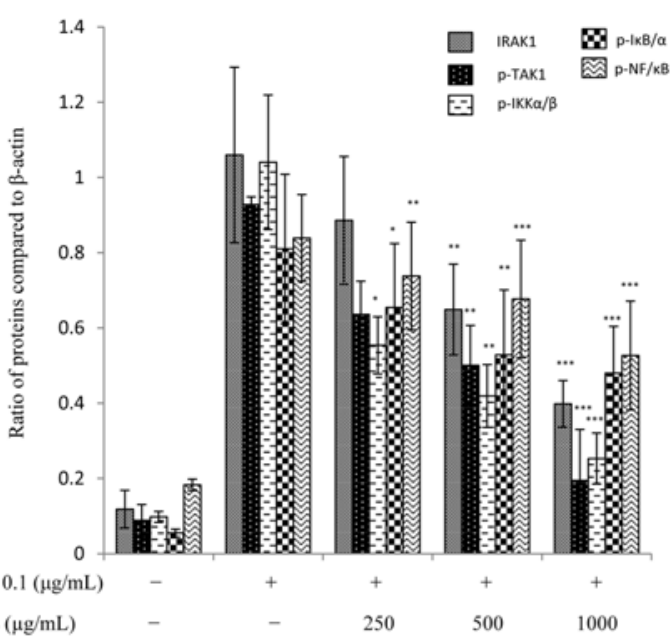

C
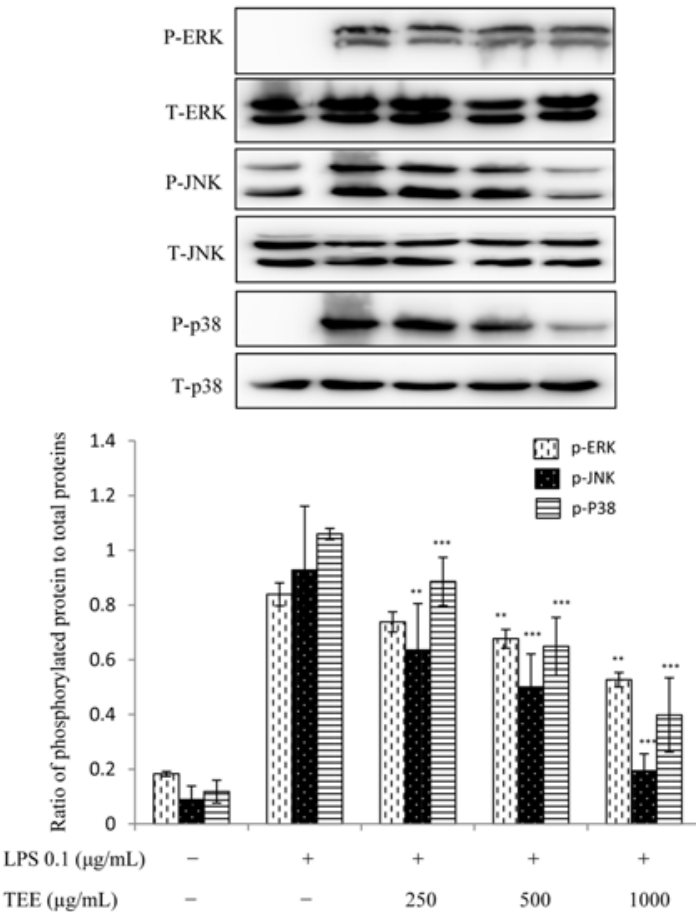

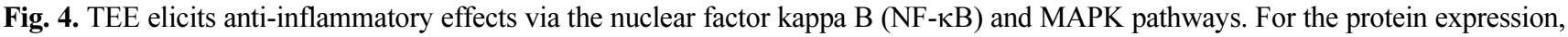
RAW 264.7 cells were treated with TEE and stimulated with LPS 30 min later. Nuclear and cytoplasmic proteins were extracted by NE-PER Nuclear and Cytoplasmic Extraction Kit (Thermo Scientific). $\beta$-actin was used as an internal control. Inhibition in the phosphorylation of all downstream NF- $\kappa B$ (A). Suppression in the phosphorylation of MAPK factors downstream (B and C). Image is representative of three independent experiments. Values in bar graph are mean $\pm \mathrm{SEM}$ of three independent experiments. ${ }^{* * *} p<0.001$, ${ }^{* *} p<0.05$ and ${ }^{*} p<0.01$ are considered significant compared to LPS group only. 


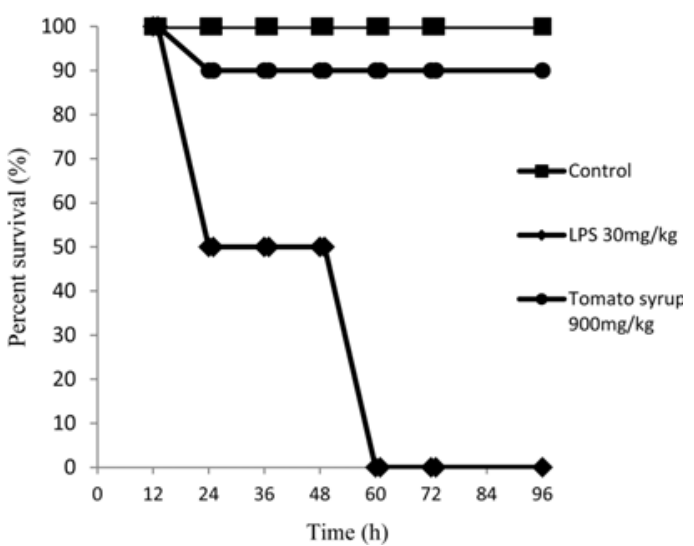

Fig. 5. Increased survival rate in mice treated with tomato syrup in a septic shock model. For septic shock model, male ICR mice were pretreated with tomato syrup at dosage of $900 \mathrm{mg} / \mathrm{kg}$ for three days and then were given LPS at $30 \mathrm{mg} / \mathrm{kg}$. Survival rates were monitored for $96 \mathrm{~h}$.

\section{Diminution of pro-inflammatory cytokines expression} levels by TEE

As shown in Fig. 3A and B, TEE had dose dependently diminished the transcriptional expression levels of the major pro-inflammatory cytokines such as IL-1 $\beta$, IL-6 and TNF- $\alpha$.

\section{Signal transduction of TEE via the NF- $\kappa$ B and MAPK pathways}

Most extracts or compounds that exhibit anti-inflammatory effects act via the NF- $\kappa$ B and MAPK pathways. As shown in Fig. 4A-C, TEE in a potent manner decreased the phosphorylation of all the downstream factors of NF- $\kappa B$ and MAPK pathways. These results clearly showed that TEE and particularly the lycopene content exhibited strong anti-inflammatory effects through which inflammatory mediators, cytokines and downstream regulating factors were suppressed.

TEE increased the survival rate in septic shock mice

The above results were the elucidation of TEE anti-inflammatory effects in vitro. This persuaded us to examine the in vivo effects of tomato syrup supplementation in mice challenged with a lethal dose of LPS i.e. $30 \mathrm{mg} / \mathrm{kg}$. Our results showed that the tomato syrup administered orally at dosage of $900 \mathrm{mg} / \mathrm{kg}$ increased the survival rates of mice dramatically as shown in Fig. 5.

\section{Discussion}

Inflammation is the phenomenon that is characterized by the microcirculation of blood cells, primarily the white blood cell types to counteract the foreign particle. This system works in harmony with many interleukins, cytokines and chemokines to bring the cellular state back to its normal condition [21]. Generally inflammation is characterized by the five cardinal signs: swelling, pain, redness, oedema and loss of sensation at the site. These outward clinical manifestations appear because of the internal battle between the foreign particle and the body's immune cells. Whenever a foreign particle invades a cell, a number of inflammatory mediators and cytokines are released that modulate or neutralize the invader [10]. NO is a gas that is released when L-arginine is oxidized by nitric oxide synthase (NOS) enzyme. It then mediates the production of pro-inflammatory cytokines to effectively recruit the other immune cells for defence mechanism [18]. The production of this gas is generally beneficial as it recruits the other pro-inflammatory mediators, however if uncontrolled, it leads to the excessive stimulation of proinflammatory mediators like iNOS and COX-2 and cytokines, IL-1 $\beta$, IL-6, and TNF- $\alpha[13,18]$.

Lycopene is a naturally occurring carotenoid synthesized in plants but not in animals or humans. It is abundantly found in tomatoes and various other fruits and vegetables. The lycopene content in the tomato can range from $8.8-42 \mu \mathrm{g} / \mathrm{g}$ of its wet weight and nearly $85 \%$ of lycopene for dietary proportion is obtained from the tomato and tomato products $[1,27]$. Numerous epidemiological studies have shown that populations consuming more tomatoes or those that have tomato as an essential component in their diets exhibit lower incidences of chronic inflammatory diseases $[2,26]$. Up till now there are many studies investigating tomato as a modulator of inflammation primarily due to the lycopene content and also because lycopene targets a wide range of molecular cell machinery $[4,20]$. As a result of NO production, transcriptional factors like iNOS and COX-2 are activated signaling the release of pro-inflammatory cytokines [34]. Our results (Figs. 1-3) have shown that TEE dose dependently inhibited the production of $\mathrm{NO}$, as well as the expression levels of iNOS, COX-2, IL-1 $\beta$, IL- 6 and TNF- $\alpha$. All these factors are the pro-inflammatory mediators that start the inflammatory cascade or pro-inflammatory cytokines that recruit the other inflammatory cells and activate downstream signalling pathways [23, 25, 35].

After investigating the preliminary suppression of these pro-inflammatory mediators and cytokines, we further moved to examine the pathways that modulate these effects. The first one to our knowledge was the NF- $\mathrm{BB}$ pathway. This is a classical pathway of inflammation and is activated when the LPS binds to the Toll-like receptor 4, leading to the disassociation, translocation and activation of its downstream components like interleukin-1 receptor-associated kinase (IRAK$1)$, transforming growth factor $\beta$-activated kinase (TAK-1), $\mathrm{IKK} \beta / \alpha, \mathrm{I} \kappa \mathrm{B} / \alpha$ and finally $\mathrm{NF}-\kappa \mathrm{B}$ in the nucleus $[11,30$, 33]. Our results in (Fig. 4A) have shown that TEE inhibited the phosphorylation of all of these downstream factors in the RAW 264.7 cells indicating that lycopene component of the tomato was indeed taken into the cell demonstrating its antiinflammatory effects under LPS stimulation [24].

MAPK pathway is a stress activated pathway. It is always activated whenever the cell experiences stress either endogenous or exogenous. [7, 17, 31] Since LPS is a bacterial 
toxin, it created stress in RAW 264.7 cells, leading to the pro-inflammatory activation of this pathway. Again, the lycopene content of tomatoes as shown in (Fig. 4B-C) has dose dependently diminished the phosphorylation of all the downstream factors associated with this pathway (i.e. MAPK kinase MEK, MKK, JNK, ERK and P38). These results indicate that TEE extract exerts its anti-inflammatory effects via the NF- $\kappa B$ and MAPK pathways.

The biggest concern of practical medical science is the avoidance of systemic inflammation that occurs as a result of post-operative sepsis or some other chronic inflammatory disease [15]. A number of studies have indicated that tomato extract or tomato products have been beneficial in the treatment of carrageenan-induced paw oedema in rat, prostatitis and colitis in rats $[3,5,9,23,28]$. However, no study to this point has investigated the effects of tomato extract in LPS induced septic shock. For this reason we induced LPS shock in mice via $30 \mathrm{mg} / \mathrm{kg}$ of LPS intraperitoneally. Our experiment showed a remarkable result that tomato syrup that was given orally for three days prior to LPS shock dramatically prolonged the survival rate of mice when compared to LPS treated mice only for a period of $96 \mathrm{~h}$ (Fig. 5). This result is the first finding to elucidate the anti-inflammatory effects of tomato in an LPS induced septic shock mouse model.

In conclusion, TEE had shown outstanding effects as an anti-inflammatory agent in RAW 264.7 cells by suppressing the production of pro-inflammatory mediators and cytokines via the NF-kB and MAPK pathways. Moreover tomato syrup dramatically increased the survival rates of mice with LPSinduced septic shock.

\section{Acknowledgments}

We thank Prof. Roh for providing us with tomato sample for experiments. Moreover we would like to acknowledge Prof. Kwak and Prof. Rhee for comments that greatly improved the manuscript. All authors declare no conflict of interest. This research was supported by the National Research Foundation of Korea Grant funded by the Korean government (grant No. 2015R1D1A1A09057204).

\section{References}

1. Agarwal A, Shen H, Agarwal S, Rao AV. Lycopene content of tomato products: its stability, bioavailability and in vivo antioxidant properties. J Med Food 2001, 4, 9-15.

2. Arab L, Steck S. Lycopene and cardiovascular disease. Am J Clin Nutr 2000, 71 (6 Suppl), 1691S-1695S; discussion 1696S-1697S.

3. Bansal P, Gupta SK, Ojha SK, Nandave M, Mittal R, Kumari S, Arya DS. Cardioprotective effect of lycopene in the experimental model of myocardial ischemia-reperfusion injury. Mol Cell Biochem 2006, 289, 1-9.

4. Basu A, Imrhan V. Tomatoes versus lycopene in oxidative stress and carcinogenesis: conclusions from clinical trials. Eur J Clin Nutr 2007, 61, 295-303.
5. Bignotto L, Rocha J, Sepodes B, Eduardo-Figueira M, Pinto R, Chaud M, de Carvalho J, Moreno H Jr, MotaFilipe H. Anti-inflammatory effect of lycopene on carrageenaninduced paw oedema and hepatic ischaemia-reperfusion in the rat. Br J Nutr 2009, 102, 126-133.

6. Camara M, Matallana MC, Sánchez-Mata MC, Ayué RL, Labra E. Lycopene and hydroxymethylfurfural (HMF) evaluation in tomato products. Acta Hortic 2003 613, 365371.

7. Chen C, Chen YH, Lin WW. Involvement of p38 mitogenactivated protein kinase in lipopolysaccharide-induced iNOS and COX-2 expression in $\mathrm{J} 774$ macrophages. Immunology 1999, 97, 124-129.

8. Driscoll KE, Carter JM, Hassenbein DG, Howard B. Cytokines and particle-induced inflammatory cell recruitment. Environ Health Perspect 1997, 105 (Suppl 5), 1159-1164.

9. Ellinger S, Ellinger J, Stehle P. Tomatoes, tomato products and lycopene in the prevention and treatment of prostate cancer: do we have the evidence from intervention studies? Curr Opin Clin Nutr Metab Care 2006, 9, 722-727.

10. Gilroy DW, Lawrence T, Perretti M, Rossi AG. Inflammatory resolution: new opportunities for drug discovery. Nat Rev Drug Discov 2004, 3, 401-416.

11. Goldring CE, Reveneau S, Pinard D, Jeannin JF. Hyporesponsiveness to lipopolysaccharide alters the composition of NF-KB binding to the regulatory regions of inducible nitric oxide synthase gene. Eur J Immunol 1998, 28, 29602970.

12. Gomes A, Fernandes E, Lima JLFC, Mira L, Corvo ML. Molecular mechanisms of anti-inflammatory activity mediated by flavonoids. Curr Med Chem 2008, 15, 1586-1605.

13. Guha M, Mackman N. LPS induction of gene expression in human monocytes. Cell Signal 2001, 13, 85-94.

14. Han CH, Yang CH, Sohn DW, Kim SW, Kang SH, Cho YH. Synergistic effect between lycopene and ciprofloxacin on a chronic bacterial prostatitis rat model. Int $\mathrm{J}$ Antimicrob Agents 2008, 31 (Suppl 1), S102-107.

15. Hodgin KE, Moss M. The epidemiology of sepsis. Curr Pharm Des 2008, 14, 1833-1839.

16. Jeong D, Irfan M, Saba E, Kim SD, Kim SH, Rhee MH. Water soluble tomato concentrate regulates platelet function via the mitogen-activated protein kinase pathway. Korean $\mathrm{J}$ Vet Res 2016, 56, 67-74.

17. Kaminska B. MAPK signalling pathways as molecular targets for anti-inflammatory therapy-from molecular mechanisms to therapeutic benefits. Biochim Biophys Acta 2005, 1754, 253262.

18. Kleinert H, Schwarz PM, Förstermann U. Regulation of the expression of inducible nitric oxide synthase. Biol Chem 2003, 384, 1343-1364.

19. Kreatsoulas C, Anand SS. The impact of social determinants on cardiovascular disease. Can J Cardiol 2010, 26 (Suppl C), $8 \mathrm{C}-13 \mathrm{C}$.

20. Li H, Deng Z, Liu R, Loewen S, Tsao R. Bioaccessibility, in vitro antioxidant activities and in vivo anti-inflammatory activities of a purple tomato (Solanum lycopersicum L.). Food Chem 2014, 159, 353-360.

21. Libby P. Inflammatory mechanisms: the molecular basis of inflammation and disease. Nutr Rev 2007, 65, S140-146.

22. Martin GS. Sepsis, severe sepsis and septic shock: changes 
in incidence, pathogens and outcomes. Expert Rev Anti Infect Ther 2012, 10, 701-706.

23. Navarrete S, Alarcon M, Palomo I. Aqueous extract of tomato (Solanum lycopersicum L.) and ferulic acid reduce the expression of TNF- $\alpha$ and IL-1 $\beta$ in LPS-activated macrophages. Molecules 2015, 20, 15319-15329.

24. Palozza P, Parrone N, Catalano A, Simone R. Tomato lycopene and inflammatory cascade: basic interactions and clinical implications. Curr Med Chem 2010, 17, 2547-2563.

25. Rafi MM, Yadav PN, Reyes M. Lycopene inhibits LPSinduced proinflammatory mediator inducible nitric oxide synthase in mouse macrophage cells. J Food Sci 2007, 72, S069-074.

26. Rao AV, Agarwal S. Role of antioxidant lycopene in cancer and heart disease. J Am Coll Nutr 2000, 19, 563-569.

27. Rao AV, Ray MR, Rao LG. Lycopene. Adv Food Nutr Res 2006, 51, 99-164.

28. Reifen R, Nissenkorn A, Matas Z, Bujanover Y. 5-ASA and lycopene decrease the oxidative stress and inflammation induced by iron in rats with colitis. J Gastroenterol 2004, 39, 514-519.

29. Ren JL, Pan JS, Lu YP, Sun P, Han J. Inflammatory signaling and cellular senescence. Cell Signal 2009, 21, 378383 .

30. Rothwarf DM, Karin M. The NF- $\kappa B$ activation pathway: a paradigm in information transfer from membrane to nucleus. Sci STKE 1999, 1999, re1.

31. Saba E, Jeon BR, Jeong DH, Lee K, Goo YK, Kwak D, Kim S, Roh SS, Kim SD, Nah SY, Rhee MH. A novel Korean red ginseng compound gintonin inhibited inflammation by MAPK and NF-kB pathways and recovered the levels of mir-34a and mir-93 in RAW 264.7 cells. Evid Based Complement Alternat Med 2015, 2015, 624132.

32. Shi J, Le Maguer M. Lycopene in tomatoes: chemical and physical properties affected by food processing. Crit Rev Biotechnol 2000, 20, 293-334.

33. Surh YJ, Chun KS, Cha HH, Han SS, Keum YS, Park KK, Lee SS. Molecular mechanisms underlying chemopreventive activities of anti-inflammatory phytochemicals: down-regulation of COX-2 and iNOS through suppression of NF- $\kappa B$ activation. Mutat Res 2001, 480-481, 243-268.

34. Turini ME, DuBois RN. Cyclooxygenase-2: a therapeutic target. Annu Rev Med 2002, 53, 35-57.

35. Zhou HY, Shin EM, Guo LY, Youn UJ, Bae K, Kang SS, Zou LB, Kim YS. Anti-inflammatory activity of 4methoxyhonokiol is a function of the inhibition of iNOS and COX-2 expression in RAW 264.7 macrophages via NF- $\kappa$ B, JNK and p38 MAPK inactivation. Eur J Pharmacol 2008, 586, 340-349. 